\title{
A TRIAL OF OIL-ADJUVANT INFLUENZA VACCINE IN A NON-EPIDEMIC SEASON
}

\author{
BY \\ R. W. HOWELL and A. N. B. STOTT \\ From the Radiological Protection Division, Authority Health and Safety Branch, Harwell, and \\ the Medical Department, Dounreay Experimental Research Establishment, U.K. Atomic Energy Authority
}

(RECEIVED FOR PUBLICATION JUNE 22, 1964)

In the autumn of 1963, 1,679 employees at two U.K.A.E.A. establishments were inoculated with a single dose $(0.25 \mathrm{ml}$.) of polyvalent oil-adjuvant influenza vaccine. In a non-epidemic winter, no significant improvement in certified sickness absence could be demonstrated in the vaccinated group when compared with a randomly selected uninoculated group. In particular, no real protection was shown, in those vaccinated, against influenza and acute upper respiratory tract infections. Once respiratory sickness had occurred the vaccine showed no significant effect on the length of sickness absence.

In this trial, unpleasant reactions to the vaccine occurred in about a quarter of the inoculated, and, in particular, a large number of participants complained of general malaise which persisted for more than two weeks. These reactions were thought to be severe enough to induce consumerresistance to routine annual immunization, which is thought to be neither justified nor acceptable in a healthy industrial population at the present stage of vaccine development. This in no way detracts from the suitability or acceptability of the vaccine to high-risk patients.

Further research and testing, which is being carried out by pharmaceutical firms, is essential, and so, too, is the need for more controlled trials to evaluate changing vaccines in different population groups.

The previous experience of the United Kingdom Atomic Energy Authority with an aqueous influenza vaccine (Meichen, Rogan, and Howell, 1962) suggested that routine annual inoculation was not justified in a large industrial population. Among others who have reached a similar conclusion, Richardson and Kilpatrick (1964) found that their three-year immunization programme had so far produced no definite benefit. Nevertheless, the introduction of polyvalent oil-adjuvant vaccines to this country, with the theoretical advantage of a much smaller dose and the possibility of a longer period of protection, led to the decision to undertake a further large-scale trial in the Authority. Salk, Bailey, and Laurent (1952) and Salk, Contakos, Laurent, Sorensen, Rapalski, Simmons, and Sandberg (1953) concluded that emulsification in light mineral oil of low viscosity greatly increases the antigenic effectiveness of influenzal virus vaccines; peak titres of antibody are significantly higher, and protective levels are maintained for longer periods, than with aqueous vaccine.
Inoculation was offered to all staff at the Springfields (Lancashire) and Dounreay (Caithness) establishments of the Authority. The oil-adjuvant vaccine used incorporated the following strains: $\mathrm{A} /$ Sing $/ 1 / 57 / \mathrm{Col}, \mathrm{B} / \mathrm{Eng} / 939 / 59, \mathrm{~B} / \mathrm{Tai} / 4 / 62$, and A/Eng/1/61.

\section{Methods}

Although the vaccine was offered to all employees, at Springfields only $\mathbf{5 5 0}$ volunteers were forthcoming compared with some 1,800 in a previous trial. It was thought that the reactions which occurred in the previous programme were largely responsible for the relatively small proportion accepting protection. Inoculation sessions were held over a period of two weeks starting on September 30.

At Dounreay, where inoculation had not previously been offered, approximately half of the staff were vaccinated over a period lasting from the end of October until November 20. A single dose of $0.25 \mathrm{ml}$. was administered from a disposable syringe 
intramuscularly into one or other of the deltoid muscles, unless an alternative site was requested. No difficulties were encountered in the administration of the vaccine.

Although Himmelweit (1963) states that there is only one strong contra-indication to influenza vaccine, 'namely hypersensitivity to eggs or chicken meat, volunteers who gave a history of allergic reaction to previous injections or had suffered from the major allergic diseases were on this occasion advised against having the vaccine.

Reactions.-An immediate reaction was rare, but within 24 hours a few patients at each establishment complained of cold or influenza-like symptoms. These effects were naturally attributed to the vaccine, but they were apparently not severe enough to be reflected in the certified sickness absence rates. A few days later, a more widespread trend became apparent at both establishments when frequent reports were received of persistent influenza-like symptoms. This feeling of malaise was to persist in many patients for several weeks, and a more recent enquiry has suggested that, in a small proportion of people, the symptom remained for several months.

At Dounreay, a questionnaire was widely distributed some two months after inoculation; $52 \%$ of those immunized ( 590 out of 1,139 persons) returned completed forms. The proportion was slightly lower than this for manual workers, with $42 \%$ of those aged 15 to 44 years returning forms, while the proportion for older men was $43 \%$. Perhaps the higher proportion of returns from non-manual workers $(68 \%)$ was not unexpected. This sample returning questionnaires was obviously likely to be biased; probably those without a reaction to the vaccine were less inclined to complete the form than those who experienced side-effects. It is difficult, too, to frame a questionnaire that is both simple and exempt from criticism. The replies on this occasion did however confirm the clinical impressions. Of those returning questionnaires, $47 \%$ reported one or more of the four major reactions.

Even if it be accepted that all who failed to return a form had no reactions (this is an extremely optimistic and unlikely assumption), the percentage with discomfort was higher (24\%) than would be considered desirable or acceptable for routine annual inoculation in industry. Some results from the questionnaire (Table 1) have been shown as a proportion of those completing the form and also of all those inoculated. The true values probably lie somewhere between the two ratios. The questions asked were not mutually exclusive. No symptoms, other than those shown, were reported in sufficiently
TABLE 1

REACTIONS ESTIMATED FROM REPLIES TO QUESTIONNAIRE

\begin{tabular}{c|c|c}
\hline Symptom & \multicolumn{1}{c|}{ Percentage of Those Who: } \\
\cline { 2 - 3 } & $\begin{array}{c}\text { Completed } \\
\text { Questionnaire }\end{array}$ & $\begin{array}{c}\text { Were } \\
\text { Inoculated }\end{array}$ \\
\hline Pain at site of injection lasting & 18 & 9 \\
$\begin{array}{c}\text { more than 24 hours } \\
\text { Fever or influenza-like illness } \\
\text { immediately after injection }\end{array}$ & 8 & 4 \\
$\begin{array}{c}\text { Swelling or inflammation of arm } \\
\text { Persistent feeling of mild influenza } \\
\text { or cold lasting several weeks }\end{array}$ & 2 & 1 \\
\hline
\end{tabular}

large numbers to be attributable to the vaccine. Such other conditions mentioned in the questionnaire replies had a normal incidence for this time of year (November).

Selection of Control Groups.-As the number inoculated at Dounreay was about half the establishment strength, it was obviously not possible to obtain a control group there which would be both random and numerically equal to the inoculated group. A control group two-thirds the size of the vaccinated group was therefore proposed, and in order to permit the ready amalgamation of the results from both establishments, a group of similar proportions was selected at Springfields. Since the proportion of female manual workers employed by the Authority is low, the comparison was restricted to male and female non-manual workers and to male manual employees. Female manual workers who volunteered were inoculated, but the results were neither analysed nor included in this report.

The random selection of controls was not carried out by staff from the establishments concerned, thereby obviating any suggestion that a knowledge of the people involved, or their health records, in any way affected the design or control of the trial. From a standard pack of Rand punched cards with a million random digits a control list was made for each establishment, and from these the required control identity numbers were obtained. Details of age, sex, length of service, and other such particulars were then obtained from the two establishments. Most manual workers were engaged on what is loosely termed 'process work', and there were a substantial number of skilled craftsmen and their mates. Salaried non-manual staff were made up of scientific, engineering, supervisory, and administrative employees. Tables 2 and 3 give details of age and staff status. The differences between the two groups were such that they could be expected to have arisen by chance.

Diagnosis and Classification.-The difficulties encountered in the diagnosis of influenza without 
TABLE 2

VACCINATED AND CONTROL GROUP NUMBERS BY AGE, SEX, AND WORK STATUS

\begin{tabular}{|c|c|c|c|c|c|c|c|c|c|}
\hline \multirow{2}{*}{ Age Group (yr.) } & \multicolumn{2}{|c|}{ Springfields } & \multicolumn{2}{|c|}{ Dounreay } & \multicolumn{4}{|c|}{ Both Establishments } & \multirow{2}{*}{$\begin{array}{c}\text { S.E. of } \\
\text { Differences }\end{array}$} \\
\hline & Vaccinated & Control & Vaccinated & Control & \multicolumn{2}{|c|}{ Vaccinated } & \multicolumn{2}{|c|}{ Control } & \\
\hline $\begin{array}{l}\text { Male non-manual } \\
\text { workers } \\
15-44 \\
45 \text { and over }\end{array}$ & $\begin{array}{r}132 \\
58\end{array}$ & $\begin{array}{l}82 \\
37\end{array}$ & $\begin{array}{r}301 \\
51\end{array}$ & $\begin{array}{r}205 \\
39\end{array}$ & $\begin{array}{l}433 \\
109\end{array}$ & $\begin{array}{l}(\%) \\
79 \cdot 9 \\
20 \cdot 1\end{array}$ & $\begin{array}{r}287 \\
76\end{array}$ & $\begin{array}{l}(\%) \\
79 \cdot 1 \\
20 \cdot 9\end{array}$ & $\begin{array}{l}(\%) \\
2 \cdot 8\end{array}$ \\
\hline Total & 190 & 119 & 352 & 244 & 542 & 100 & 363 & 100 & \\
\hline $\begin{array}{l}\text { Male manual workers } \\
15-44 \\
45 \text { and over }\end{array}$ & $\begin{array}{l}177 \\
151\end{array}$ & $\begin{array}{r}125 \\
97\end{array}$ & $\begin{array}{l}506 \\
216\end{array}$ & $\begin{array}{l}315 \\
156\end{array}$ & $\begin{array}{l}683 \\
367\end{array}$ & $\begin{array}{l}65 \cdot 0 \\
35 \cdot 0\end{array}$ & $\begin{array}{l}440 \\
253\end{array}$ & $\begin{array}{l}63 \cdot 5 \\
36 \cdot 5\end{array}$ & $2 \cdot 3$ \\
\hline Total & 328 & 222 & 722 & 471 & 1,050 & 100 & 693 & 100 & \\
\hline $\begin{array}{l}\text { Female non-manual } \\
\text { workers } \\
15-44 \\
45 \text { and over }\end{array}$ & $\begin{array}{r}21 \\
1\end{array}$ & $\begin{array}{r}18 \\
1\end{array}$ & $\begin{array}{r}60 \\
5\end{array}$ & $\begin{array}{r}40 \\
4\end{array}$ & $\begin{array}{r}81 \\
6\end{array}$ & $\begin{array}{r}93 \cdot 1 \\
6.9\end{array}$ & $\begin{array}{r}58 \\
5\end{array}$ & $\begin{array}{r}92 \cdot 1 \\
7 \cdot 9\end{array}$ & $4 \cdot 3$ \\
\hline
\end{tabular}

TABLE 3

GROUP PROPORTIONS BY SEX AND WORK STATUS

\begin{tabular}{l|r|r|c}
\hline & \multicolumn{2}{|c|}{ Springfields and Dounreay Combined } \\
\cline { 2 - 3 } & $\begin{array}{c}\text { Vaccinated } \\
\text { Group }\end{array}$ & $\begin{array}{c}\text { Control } \\
\text { Group }\end{array}$ & $\begin{array}{c}\text { S.E. of } \\
\text { Differences (\%) }\end{array}$ \\
\hline $\begin{array}{l}\text { Male non-manual } \\
\text { workers }\end{array}$ & $542(32.3 \%)$ & $363(32.4 \%)$ & 1.8 \\
$\begin{array}{l}\text { Male manual } \\
\text { workers }\end{array}$ & $1,050(62.5 \%)$ & $693(61.9 \%)$ & 1.9 \\
$\begin{array}{l}\text { Female non- } \\
\text { manual workers }\end{array}$ & $87(5.2 \%)$ & $63(5.6 \%)$ & 0.9 \\
\hline Total & $1,679(100 \%)$ & $1,119(100 \%)$ & \\
\hline
\end{tabular}

laboratory confirmation are well known, but it is not proposed to discuss again the validity of morbidity rates based on general practitioner certificates (Meichen et al., 1962; Norman and Spratling, 1956).

In this text, the diagnoses given imply classification under the International Statistical Classification (Table 4).

TABLE 4

\begin{tabular}{l|c}
\hline \multicolumn{1}{c|}{ Diagnosis } & Code Number(s) \\
\hline $\begin{array}{l}\text { Influenza } \\
\text { Acute upper respiratory tract infection }\end{array}$ & $480-482$ \\
(U.R.T.I.) & $470-475$ \\
Bronchitis & $500-502$ \\
All other respiratory conditions & $510-527,490-493,783$ \\
\hline
\end{tabular}

Previous Influenza Immunization.-All volunteers at Springfields were asked the dates of previous influenza inoculation, since evidence of recent immunization might well mean that any beneficial effect demonstrated in the vaccinated group derived not solely from the oil-adjuvant vaccine but from the cumulative effect of past and present experience. Evidence of recent vaccination might well mean, too, that the control group had a proportion with some residual protection, thus making invalid a comparison on the basis of one group with recent protection and the other unprotected. However, an analysis of the returns from the inoculated group showed that aithough a proportion had been immunized three years previously (with an aqueous vaccine having a protective effect for a very limited period), none had had a recent inoculation from either a general practitioner or any other source. In view of this, it seemed reasonable to regard the control group, too, as being unprotected.

In the more rural environment of Dounreay, it was easy to confirm from local practitioners that previous inoculation was neither common nor recent and that both groups could be regarded as being hitherto unprotected.

Comparability of the Two Groups.-Since volunteers are obviously self-selecting, they may well differ in important characteristics from the population from which they are drawn. It would therefore be unwise to compare these volunteer and control groups without some assessment of their past medical history, quite apart from factors such as age, sex, and work status. Previous certified sickness absence due to respiratory disease was therefore reviewed for the period January 1, 1963 until September 30, 1963 in the case of Springfields, and until October 31, 1963 for Dounreay. From records maintained routinely on punched cards, information was obtained for the two groups. However, not all of the vaccinated, nor all the controls, were at risk for the whole period under review, since newly recruited staff had joined both establishments. A check revealed that not only were the numbers joining small compared with those who had been in service for the whole of 1963 , but also that there were no significant differences between 
TABLE 5

STAFF WITH RESPIRATORY ABSENCE BEFORE VACCINATION

\begin{tabular}{|c|c|c|c|c|c|c|}
\hline \multirow{2}{*}{ No. of Persons } & \multicolumn{2}{|c|}{ Springfields } & \multicolumn{2}{|c|}{ Dounreay } & \multicolumn{2}{|c|}{ Both Establishments } \\
\hline & Vaccinated & Control & Vaccinated & Control & Vaccinated & Control \\
\hline $\begin{array}{l}\text { At risk } \\
\text { With no absence } \\
\text { With one absence } \\
\text { With two absences } \\
\text { With three or more absences }\end{array}$ & $\begin{array}{r}540 \\
430 \\
99 \\
9 \\
2\end{array}$ & $\begin{array}{r}360 \\
291 \\
63 \\
6 \\
0\end{array}$ & $\begin{array}{r}1,139 \\
793 \\
271 \\
57 \\
18\end{array}$ & $\begin{array}{r}759 \\
529 \\
182 \\
37 \\
11\end{array}$ & $\begin{array}{l}1,679 \\
1,223(72 \cdot 8 \%) \\
370 \\
66 \\
20\end{array}$ & $\begin{array}{l}1,119 \\
820 \\
245 \\
43 \\
11\end{array}$ \\
\hline
\end{tabular}

*Standard error of percentage difference $=1 \cdot 7$; not significant at $5 \%$ level.

TABLE 6

PERCENTAGE OF STAFF, BY RESPIRATORY GROUPINGS, WITH ABSENCE' BEFORE VACCINATION

\begin{tabular}{l|c|c}
\hline \multicolumn{1}{c|}{ Diagnosis } & \multicolumn{2}{c}{ Springfields and Dounreay } \\
\cline { 2 - 3 } & \multicolumn{1}{c|}{ Vaccinated } & Control \\
\hline Acute U.R.T.I. & $10 \cdot 0$ & $10 \cdot 0$ \\
Influenza & $13 \cdot 5$ & $13 \cdot 9$ \\
Bronchitis & $4 \cdot 1$ & $3 \cdot 2$ \\
All other respiratory episodes & $2 \cdot 6$ & $2 \cdot 5$ \\
All respiratory episodes combined & $27 \cdot 2$ & $26 \cdot 7$ \\
\hline
\end{tabular}

the control and vaccinated groups. At Springfields, new staff represented $1.5 \%$ of the total numbers in the inoculated group, compared with $1.7 \%$ in the control group, whereas at Dounreay the figures were respectively $5.0 \%$ and $5.5 \%$. The rates for both establishments combined were $3.7 \%$ and $4 \cdot 1 \%$, a not significant difference.

The percentages of staff experiencing sickness absence before inoculation are given in Tables 5 and 6. More elaborate tabulations have been omitted in the interests of brevity.

Antibody Production.-Since it was impossible to assess the effectiveness of the vaccine on clinical grounds because of the absence of an epidemic, it was comforting to know that the production of antibodies was satisfactory. Blood samples were taken from 37 of those vaccinated at Springfields and from an equal number of non-vaccinated volunteers who attended for routine medical re-examination. $\mathrm{Al}$ though these samples were not absolutely random, there was no reason to suppose that they were atypical. Titrations for antibodies to influenza $\mathrm{A}$ and $B$ were done on all serum pairs. An antibody

TABLE 7

GEOMETRIC MEAN TITRES IN 37 VACCINATED VOLUNTEERS

\begin{tabular}{l|l|c|c}
\hline \multicolumn{1}{c|}{ Strain } & Time & $\begin{array}{c}\text { Geometric } \\
\text { Mean } \\
\text { Titre }\end{array}$ & $\begin{array}{c}\text { No. of } \\
\text { Persons with } \\
\text { Titre } ₹ 1 / 48\end{array}$ \\
\hline A/Sing & Before vaccination & $29 \cdot 4$ & $24(64 \cdot 9 \%)$ \\
A/Sing & 3 months after vaccination & $961 \cdot 6$ & 0 \\
B/Eng. & Before vaccination & 23.0 & $22(59.5 \%)$ \\
B/Eng. & 3 months after vaccination & $259 \cdot 8$ & 1 \\
\hline
\end{tabular}

response was confined to those who received the vaccine, supporting the view that none of the observed rise in antibody was due to intercurrent natural infection rather than to the vaccine. In general, these results showed a highly satisfactory response to oil-adjuvant vaccine (Table 7) with levels well above the minimum generally considered adequate to confer protection against clinical influenza, and of the order which could be expected from the results of the recent Medical Research Council trial (Hobson, Lane, Beare, and Chivers, 1964). Indeed it is gratifying to note that the antibody response to this polyvalent vaccine was similar to that derived from the monovalent vaccines used in the M.R.C. trial.

\section{Results of Present Investigation}

From the previous analyses, it was concluded that there was sufficient justification for regarding the two groups as suitable for a post-vaccination review. It was considered desirable that the month in which inoculation was done should be capable of isolation from the rest of the review period to March 31, 1964, since the vaccinations were spread over two weeks or more, and a further 14 days might be regarded as a reasonable period in which protection might be attained. The term 'vaccination month' therefore means October 1963 for Springfields and November 1963 in the case of Dounreay. Figures for November (where this is not the vaccination month) are therefore derived from Springfields data alone.

During the period under review, normal resignations, retirements, and deaths occurred, and there were two simple courses which could be taken to allow for the effects of this staff wastage. Either those leaving before March 31 could be withdrawn completely from the trial, or, if the proportion was both small and similar in the two groups, then the loss could be ignored. The proportions of staff leaving before March 31 were $2 \cdot 2 \%$ in the vaccinated group and $3.1 \%$ in the control group at Springfields; the Dounreay figures were respectively $2.2 \%$ and $1.7 \%$. In fact, the results were very similar by either method (more sophisticated treatment did not seem 
TABLE 8

POST-VACCINATION RESPIRATORY EPISODES BY MONTH OF ONSET AND DISEASE GROUPINGS

\begin{tabular}{|c|c|c|c|c|c|c|c|c|c|c|c|c|c|c|}
\hline \multirow{3}{*}{ Diagnosis } & \multicolumn{14}{|c|}{ Springfields and Dounreay } \\
\hline & \multicolumn{7}{|c|}{ Vaccinated Group } & \multicolumn{7}{|c|}{ Control Group $\dagger$} \\
\hline & $\begin{array}{l}\text { Vacc. } \\
\text { Month }\end{array}$ & Nov.* & Dec. & Jan. & Feb. & Mar. & Total & $\begin{array}{l}\text { Vacc. } \\
\text { Month }\end{array}$ & Nov.* & Dec. & Jan. & Feb. & Mar. & Total \\
\hline $\begin{array}{l}\text { Acute U.R.T.I. } \\
\text { Influenza } \\
\text { Bronchitis } \\
\text { All other }\end{array}$ & $\begin{array}{r}20 \\
23 \\
4 \\
4\end{array}$ & $\begin{array}{l}2 \\
3 \\
1 \\
0\end{array}$ & $\begin{array}{r}27 \\
15 \\
5 \\
3\end{array}$ & $\begin{array}{r}25 \\
20 \\
10 \\
1\end{array}$ & $\begin{array}{r}15 \\
30 \\
3 \\
5\end{array}$ & $\begin{array}{r}10 \\
16 \\
5 \\
1\end{array}$ & $\begin{array}{l}79 \\
84 \\
24 \\
10\end{array}$ & $\begin{array}{c}24 \\
19 \frac{1}{2} \\
3 \\
10 \frac{1}{2}\end{array}$ & $\begin{array}{l}3 \\
7 \frac{1}{2} \\
6 \\
1 \frac{1}{2}\end{array}$ & $\begin{array}{r}21 \\
25 \frac{1}{2} \\
4 \frac{1}{2} \\
4 \frac{1}{2}\end{array}$ & $\begin{array}{l}22 \frac{1}{2} \\
16 \frac{1}{2} \\
15 \\
3\end{array}$ & $\begin{array}{c}18 \\
25 \frac{1}{2} \\
3 \\
4 \frac{1}{2}\end{array}$ & $\begin{array}{c}21 \\
13 \frac{1}{2} \\
0 \\
3\end{array}$ & $\begin{array}{l}85 \frac{1}{2} \\
88 \frac{1}{2} \\
28 \frac{1}{2} \\
16 \frac{1}{8}\end{array}$ \\
\hline \multirow[t]{3}{*}{ Total } & 51 & 6 & 50 & 56 & 53 & 32 & 197 & 57 & 18 & $55 \frac{1}{2}$ & 57 & 51 & $37 \frac{1}{2}$ & 219 \\
\hline & & \multicolumn{6}{|c|}{197} & \multicolumn{7}{|c|}{219} \\
\hline & \multicolumn{7}{|c|}{248} & \multicolumn{7}{|c|}{276} \\
\hline
\end{tabular}

*Springfields only. This was vaccination month for Dounreay.

†Since the control group was numerically two-thirds of the vaccinated group, the actual number of episodes for the control group has been increased by $50 \%$ to permit direct comparison.

necessary), and Table 8 shows the number of episodes for both establishments by month of onset of absence, and in the various respiratory groupings. The combined rates were $2 \cdot 2 \%$ for the inoculated group and $2 \cdot 1 \%$ for the controls. The proportion of staff absent with a diagnosis of influenza was $4.8 \%$ in the inoculated group and $5.1 \%$ in the control group-a difference not significant at the $5 \%$ confidence level.

As the protection afforded in a non-epidemic season is quite clearly below that which most investigators would consider a desirable level, other tabulations suitable for formal significance tests, and rates giving days lost and episodes per 100 at risk, have been omitted; so, too, have tables for the separate establishments, since the pattern was very similar at each.

In the previous Authority investigation, a greater protective effect was found in those aged 45 and over, but in this study the results were similar at each establishment for both age groups.

All certified sickness absence has been included regardless of duration. In fact, in the vaccinated group there were 18 episodes of less than four days' duration. The control group, with a numerical strength two-thirds that of the vaccinated group, had 15 such episodes.

Once sickness had occurred, the length of absence was similar in both groups, and there was no evidence that the vaccine significantly reduced the severity of influenza and other diseases in those who lost time from work. The vaccinated group did show a slightly improved average length of absence in three diagnostic groups (Table 9).

\section{Discussion}

In such a period of limited influenza incidence,
TABLE 9

AVERAGE LENGTH OF EPISODE BY DIAGNOSTIC GROUP

\begin{tabular}{|c|c|c|}
\hline Diagnosis & $\begin{array}{l}\text { Vaccinated } \\
\text { Group } \\
\text { (days) }\end{array}$ & $\begin{array}{l}\text { Control } \\
\text { Group } \\
\text { (days) }\end{array}$ \\
\hline $\begin{array}{l}\text { Acute U.R.T.I. } \\
\text { Influenza } \\
\text { Bronchitis } \\
\text { All other respiratory diagnoses }\end{array}$ & $\begin{array}{r}9 \cdot 3 \\
12 \cdot 5 \\
16 \cdot 1 \\
14 \cdot 2\end{array}$ & $\begin{array}{l}10 \cdot 6 \\
13 \cdot 1 \\
19 \cdot 6 \\
12 \cdot 6\end{array}$ \\
\hline All episodes & $11 \cdot 8$ & 12.9 \\
\hline
\end{tabular}

perhaps few practitioners would hope for the degree of protection reported by Meiklejohn (1962) in a group of over 2,000 men inoculated with a combined influenza and adenovirus vaccine. In his series, compared with 35 hospitalized cases of influenza in the control group, only two were reported among the vaccinated. Nevertheless, it is disappointing to find that with over 80 cases in the vaccinated group in this present series, no worthwhile protective effect could be demonstrated. Perhaps it should be reemphasized that the diagnosis of influenza was entirely clinical, and that the true number of cases might have been smaller.

It is now generally accepted that sickness absence in industry reflects more than physical and mental illness, and that morale, sick pay schemes, domestic responsibilities, and other factors affect such rates. It may well be that the clinical protection offered by influenzal vaccines is greater than is often demonstrated in industrial sickness absence rates. Indeed, the relatively generous sick pay scheme in operation in the Authority may well have a considerable effect on such rates. On the other hand, there is little advantage to management if the prevention of clinical influenza merely results in absence for an alternative reason, although it is fair to say that no evidence was obtained that such alternative absences occurred. 
The cost of a large immunization programme is quite considerable. In addition to the relatively high cost of the vaccine itself (say 6s. per head, depending on the numbers involved) on average half an hour's working time may be lost per person. The benefits derived from inoculation must therefore be apparent to justify annual routine immunization.

From the volunteer's point of view, acceptability of the vaccine and confidence in its benefits are likely to affect the numbers attending for annual inoculation. Richardson and Kilpatrick (1964) found considerable 'consumer resistance' over a period of three consecutive years, and experience at Springfields tends to confirm their experience. The impression gained at Dounreay, after such a good initial response, is that any future offer of protection would meet with a much smaller number of volunteers.

One reason for this consumer resistance in the Authority is undoubtedly the reactions which have occurred in the two large-scale investigations carried out. In the first, severe reactions within 24 hours of inoculation deterred many volunteers who withdrew before their turn for inoculation came round. In this present series, the persistence of influenza-like feelings for two or more weeks will undoubtedly dissuade many from repeating the experience. This side-effect was prevalent in both manual and nonmanual workers, in both sexes, and throughout all age groupings. It is unlikely to have been psychogenic, nor are these people likely to be restricted to those with low pain thresholds, since if this were so a very high proportion of them might be expected to have complained of pain at the site of injection. From the questionnaire, $23 \%$ of those complaining of this side-effect also reported pain of more than 24 hours' duration at the injection site. Of those completing the questionnaire, but not complaining of persistent malaise, $15 \%$ reported such pain at the injection site. These widespread influenza-like reactions were unlikely to have been caused by the oil-emulsifier since similar reactions have not generally been reported with this emulsion (and an aqueous vaccine of the same strains also produced these effects (Howell and Mackenzie, 1964)), nor was such a large sample of the population likely to have been hypersensitive. The most probable cause was toxicity of the strains incorporated in the vaccine. This poses a strong challenge to manufacturers. Obviously, the strains in a polyvalent vaccine must be changed to meet anticipated variations in the influenza expected, but since small changes in content may drastically alter the acceptability of the vaccine, intensive testing of this factor must be undertaken before general distribution.

The incidence of pain lasting more than 24 hours at the site of injection was perhaps surprisingly high at an estimated 9 to $18 \%$, but many of those who returned forms also pointed out that the discomfort was slight. It is difficult to estimate the consumer resistance that this sort of reaction provokes.

The value of large-scale annual re-inoculation with polyvalent vaccine still appears to be unproven in a healthy industrial population, although this type of vaccine might prove a good insurance measure in a year when an epidemic was confidently forecast. Its acceptability to healthy volunteers might be improved on such occasions if this aspect were emphasized. The case for further research by the pharmaceutical firms is strong, and so, too, is the need for more controlled trials to evaluate improvements as they arise. The present improved vaccines make even more compelling the inoculation of the high-risk patient.

Since no protective effect could be demonstrated on this occasion, no idea was obtained of the duration of the vaccine's efficacy, but because of the possibility that it could extend for more than 12 months (Medical Research Council Report, 1964), a further analysis of sickness absence in the two groups will be made if there is any considerable level of influenza next winter.

It is worth noting that although no major allergy reactors were vaccinated, there were no reactions of an allergic nature from minor (e.g., mild asthma) or unknown allergy subjects.

An enquiry of the two major public health laboratories in the vicinity of the establishments involved showed that the vaccine was potentially effective against circulating strains. The north of Scotland laboratory reported that the incidence of infections of the upper respiratory tract attributable to viruses was considerably lower than in recent years, and that there were remarkably few adenovirus referrals.

We are grateful to Dr. T. E. Graham and Dr. F. W. Meichen for their interest in this study and for their permission to examine the medical records of their patients at the Springfields Works of the U.K.A.E.A.

\section{REFERENCES}

Himmelweit, F. (1963). Brit. J. clin. Pract., 17, 661.

Hobson, D., Lane, C. A., Beare, A. S., and Chivers, C. P. (1964). Hobson, D., Lane, C., 2, 271

Howell, R. W., and Mackenzie, A. B. (1964). U.K.A.E.A. Report A.H.S.B. $(R P)$ R46

Medical Research Council Report (1964). Brit. med. J., 2, 267. Meichen, F. W., Rogan, E., and Howell, R. W. (1962). Brit.J. industr. Med., 19, 203

Meiklejohn, G. (1962). J. Amer. med. Ass., 179, 594.

Norman, L. G., and Spratling, F. J. (1956). Health in Industry: A Contribution to the Study of Sickness Absence, p. 16. (London Transport Executive). Butterworth, London.

Richardson, I. M., and Kilpatrick, S. J. (1964). Med. Offr., 111, 5.

Salk, J. E., Bailey, M. L., and Laurent, A. M. (1952). Amer. J. Hyg., 55, 439.

-, Contakos, M., Laurent, A. M., Sorensen, M., Rapalski, A. J., Simmons, I. H., and Sandberg, H. (1953). J. Amer. med. Ass., 151, 1169. 